\title{
International Economic Integration: Comparing Exports and FDI Networks in the New Millennium
}

\author{
Adelaide Baronchelli ${ }^{1} \&$ Teodora Erika Uberti ${ }^{2}$ \\ ${ }^{1}$ Dipartimento di Economia, Università degli Studi di Verona, Verona, Italy \\ ${ }^{2}$ Dipartimento di Economia Internazionale, Delle Istituzioni e Dello Sviluppo (DISEIS), Università Cattolica del \\ Sacro Cuore, CSCC Università Cattolica del Sacro Cuore, Milano, Italy; CRENoS, Università Degli Studi di \\ Cagliari, Cagliari, Italy \\ Correspondence: Teodora Erika Uberti, Università Cattolica del Sacro Cuore, largo Gemelli 1, 20123 Milano, \\ Italy. Tel: 3902-7234-2996.
}

Received: July 18, 2021

Accepted: October 5, 2021

Online Published: October 12, 2021

doi:10.5539/ijef.v13n11p34

URL: https://doi.org/10.5539/ijef.v13n11p34

\begin{abstract}
Trade and foreign direct investments (FDI) represent the real and the capital side of international economic integration. While Network Analysis (NA) on world trade network (WTN) is wide, few analyses describe world investment networks (WIN), since FDI data suitable for comparison are very scarce and very complex to collect. In this paper, we exploit FDI Bilateral Statistics by UNCTAD (2014), to compare WTN and WIN in the first decade of the new millennium, before and after 2008 crisis. Results show that all countries are integrated since there are few isolated economies, and unique largest components emerge confirming the complexity of global value chain. 2008 economic crisis affected WTN, but not WIN. Geography, rather than economic similarity, is crucial in defining trading connections and cohesive subgroups. WIN and WTN links are mutual in all networks, confirming that once a link is established, it is easier to maintain all commercial relations. WIN and WTN key players are USA, Germany and China for Exports, while USA and Germany for FDI. There is a positive association between couplets of WTN and WIN links, conjecturing that FDI and Exports networks could be complements, rather than substitute.
\end{abstract}

Keywords: multi-layer network analysis, economic integration, FDI, exports

\section{Introduction}

Economic integration has several facets (O’Rourke \& Williamson, 2002): flowing of goods and services, but also labour and capital movements, such as foreign direct investments (FDI). According to OECD (2002), FDI is a part of the international economic system, playing the role of "catalyst" to development, allowing the access to international markets and new technologies, and transferring intangible assets. Thanks to the innate network feature of economic integration, i.e. flows originate in a county and reach another country, Network Analysis (NA) is a suitable tool of analysis to study it. NA is particularly diffused to study world trade network (Serrano \& Boguna, 2003; Barigozzi, Fagiolo, \& Garlaschelli, 2010; Fagiolo, 2010; De Benedictis \& Tajoli, 2011; Zhou, $\mathrm{Wu}, \& \mathrm{Xu}, 2016$ ). While NA on FDI is rarer (Bing, Zefang, \& Lijian, 2018, Baronchelli \& Uberti, 2018), since FDI are far more complex than trade to measure, have a multidimensional nature (Dunning, 2009), are measured as stocks or flows, inward and outward and matching between these figures is not always straightforward (Note 1) (UNCTAD, 2009). Furthermore, only recently suitable bilateral data are available (UNCTAD, 2014).

In this NA we exploit bilateral statistics on trade and FDI (UNCTAD, 2014, 2016) in the first decade of 2000's, according to single- and multi-layer perspectives evaluating the real and financial side of worldwide economic integration.

Figure 1 focuses on the evolution of merchandised exports, FDI outward stocks and GDP since 1980 (as base year). Economic integration is at place and faster than GDP growth. Secondly, FDI pace is exponential and faster than exports since it is enhanced by the liberalisation of regulations on the movement of capital flows. Finally, 2008-09 financial crisis affected Exports but not FDI, hence the financial economic integration did not stop.

If Figure 1 depicts the evolution of economic integration, its networking part is completely missing. Hence, in this paper we aim to verify structural similarities a/o differences between the world investment network (WIN) 
and the world trade network (WTN) in the first decade of the new millennium; and secondly, according to a multi-layer perspective, we focus on WIN and WTN communities in order to analyse their membership evolution in reaction to exogenous economic shocks.

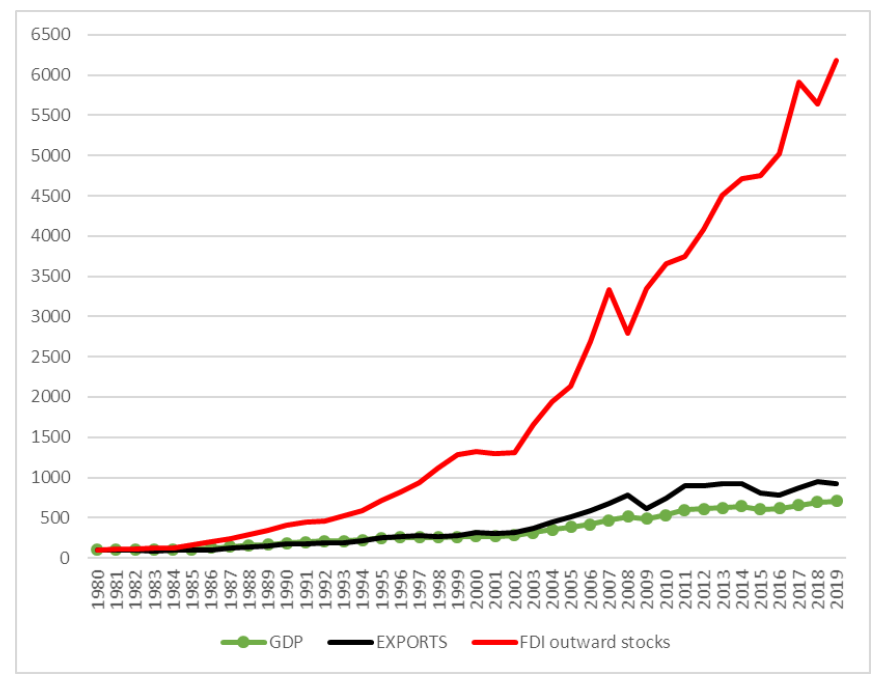

Figure 1. Worldwide GDP, Exports, FDI outward stocks (1980=100)

Source: authors' elaboration based on UNCTAD (2020).

The paper is organised as follows: section 2 presents the literature on NA and on FDI and trade, section 3 includes NA methodology, the data and the sample of countries; section 4 includes the main results of the empirical analysis; and section 5 concludes the paper.

\section{Literature Review}

Social Network Analysis (SNA) is an interdisciplinary approach applying mathematical, statistical, computing methods in order to study (social) networks. "A social network is a set of socially relevant nodes connected by one or more relations. Nodes, or network members, are the units that are connected by the relations whose patterns we study. These units are most commonly persons or organizations, but in principle any units that can be connected to other units can be studied as nodes" (Marin \& Wellman, 2011, p. 11).

As stated in Freeman (2014), "social network analysis as an approach that involved four defining properties: (1) It involves the intuition that links among social actors are important; (2) it is based on the collection and analysis of data that record social relations that link actors; (3) it draws heavily on graphic imagery to reveal and display the patterning of those links; and (4) it develops mathematical and computational models to describe and explain those patterns" (p. 26).

NA analyses relations among social agents and handles their attributes as determinants of relations; defines positions, groups and hierarchical structures; and evaluate the overall structure of networks and centrality of agents in the network.

In ' 30 s, the pioneers were sociologists, social psychologists and anthropologists that, using mathematical and statistical tools and graph theory, analysed the concept of networks of relations linking social entities.

In economics, the application of NA was limited to verify world system theories (Wallersteien, 1974) and dependencia theories (Prebish, 1962). According to these theories, the world economic system was divided into a "developed" center, which exports manufactured goods to a "developing" periphery, which produces exclusively primary goods. Hence, developing countries economic situation was due to the existing international economic relations, and not to their cultural habits and/or institutional design. The seminal work collecting these theories is Snyder and Kick (1979).

SNA was an intriguing tool since, thanks to its techniques, allowed to describe these structural theories. During '80s and '90s, SNA techniques were adopted to detect trading "cohesive" groups and sub-groups (Nemeth \& Smith, 1985; Su \& Clawson, 1994), and how trading groups change according to imports or exports in different categories of goods (Breiger, 1981; Nemeth \& Smith, 1985; Smith \& White, 1992; Su, 1995; Van Rossem, 1996). 
With the beginning of 2000s, some circumstances radically changed the use of SNA in social sciences: the cross-fertilisation with computer science and physics approach, the diffusion of user-friendly software and together with the diffusion of reliable and suitable relational data.

"The effects of physics on SNA was to draw on ideas from social network analysis and used analytic tools developed in that field. They refined existing tools and developed new ones. Sometimes they reinvented established tools and sometimes they rediscovered known results, but often they contributed important new ways to think about and analyze network data." (Freeman, 2014, p. 35).

Watts \& Strogatz (1998) durst off the small-world theory by Milgram (1967), hence re-define and link the concepts of "clustering coefficient" and "average path length" in a socio-graph, or in any complex network structure. Barabási and Albert (1999), focusing on the degree distribution in complex networks, reintroduce the concept that few agents are very central in networks, and the degree distribution is skewed as it happens in scale-free networks. In addition, they formalise the evolution of a network: when new nodes are included in a network, they do not randomly link with other nodes, but follow a "preferential attachment", i.e. new nodes link to already central nodes reinforcing the so called "Matthew effect" (or richer get richer effect).

Newman (2003) focuses on communities' formation: firstly, the assortative mixing mechanism justifies that links are not randomly distributed in a network, but the similarity of attributes of nodes affects the probability that nodes are linked through relations; secondly the relevance of "links" betweenness in constituting (or demolishing) communities.

Since then, SNA diffused in several disciplines, especially in mainstream approaches but it started losing its "social" adjective to become a broader technique applied in many fields. In economics NA applications are particularly suitable for macroeconomic bilateral phenomena, such as WTN (Serrano \& Boguna, 2003; Barigozzi et al., 2010 and 2011; De Benedictis \& Tajoli, 2011; Fagiolo, 2010; Zhou et al., 2016), migrations, (Fagiolo \& Mastrolillo, 2014), investments (Metulini, Riccaboni, Sgrignoli, \& Zhu, 2017; Dueñas, Mastrandrea, Barigozzi, \& Fagiolo, 2017).

Many papers detect the evolution and structure WTN, but so far, few empirical studies on FDI have been carried out for two main reasons: data availability and complexity of FDI theories.

Firstly, the analysis of WIN was less diffused and limited to small groups of countries (Kim \& Park, 2012; Economou, Hassapis, Philippas, \& Tsionas, 2017), since data were not available at bilateral level. Differently from trade data, FDI data are much more complex to define and to compute according to a common standard. In addition, FDI could be stocks and flows, and in many cases the difference between stocks values is not matching with reported flows. Moreover, contrary to trading data, FDI data could be negative, indicating disinvestments, measured as negative FDI stocks (or flows), and this makes any NA much more complex than trade. UNCTAD published a database on Bilateral FDI Statistics at worldwide level in 2014, hence this paper exploits a part of it.

In addition, the economic literature on FDI, dated back in mid ' 30 s with the explanation of international capital movements based on interests rate differentials (Iversen, 1936), was never clear-cut on the determinants of FDI. Since then economic literature tried to explain FDI as an extension of the Heckscher-Ohlin framework (Mundell, 1957; MacDougall, 1960; Kemp, 1964), rather than firms monopolistic power due to superior technology, managerial expertise, patents (Kindleberger, 1969), the theory of product life-cycle (Vernon, 1966) and finally strong association between propensity to invent new products, export performance, FDI, the ratio of local production and exports and R\&D expenditure of US industries (Gruber, Mehta, \& Vernon, 1967). A twist on economic theories on FDI was during late 70's with Dunning's eclectic paradigm (Dunning, 1977, 1979). Connecting the internalization theory and trade theories, Dunning's eclectic paradigm includes three basic advantages for firms operating abroad: ownership (O), location (L) and internationalization (I). Ownership advantages refer to those assets such as pioneering technology, exclusive productive processes, patents, management skills and so on, that provide a firm with competitive advantage over other firms. Location advantages involve those conditions that attracted firms' investments to a given location such as favourable tax regimes, lower production and transport costs, market size, access to protected markets and lower risk. Internalization advantages derived from the reduction of the impact of market imperfections allowing for a reduction in transaction costs and a minimization of technology imitation and the maintenance of the firm's reputation.

Another turning point of the economic analysis on FDI is related to the New Trade Theory (Krugman, 1980). The combination of international production and trade theories produced models with a definition of "horizontal" and "vertical" FDI. According to "horizontal" models of FDI, a firm has to face the decision to serve a foreign market either by exporting its products or by producing them in the destination market. This choice is the result 
of the trade-off between advantages of keeping production closer to costumers, facing additional fixed costs of establishing a new plant in a foreign market, and the advantages of concentrating production in the home country achieving economies of scale, but dealing with trade costs (Markusen, 1984; Horstmann \& Markusen, 1987; Brainard, 1997). Key factors in this choice are trade costs, firm-level and plant level economies of scales. Firm-level economies are fundamental for FDI since they are linked to inputs which can be easily used in different plants with negligible costs. "Vertical" FDI models explain a firm's decision to locate production in a foreign market as function of large differences in factor endowments and factor prices between countries (Helpman, 1985). According to these models, a firm choosing to divide its production in different countries is mainly attracted by the possibility of exploiting lower costs of production, given that the cost of fragmentation of the production is not too high (Dixit \& Grossman, 1982; Deardorff, 2001; Jones \& Kierzkowski, 2005).

A strand of literature about FDI determinants focused on the effects that some political and institutional variables had on the decision of a firm of undertaking FDI (Bond \& Samuelson, 1986; Black \& Hoyt, 1989; Hubert \& Pain, 2002; Bénassy-Quéré, Coupet, \& Mayer, 2007).

So far, the literature faced the issue on the theoretical determinants of FDI, but what is relevant to understand are the factors that lead a firm to produce its products abroad instead of producing them in domestic plants and, then, exporting (Dunning \& Lundan, 2008). Hence, it is crucial to understand the relation between trade and FDI, if they are complements or substitute. The issue whether outward FDI substitute or stimulate exports has been addressed differently accordingly to different theoretical explanations for FDI.

Dunning argued that firms face the choice whether to produce the product in the foreign country rather than producing it in domestic plants and then exporting. Location advantages, such as artificial and natural trade barriers, low costs for factors of production and ease of access to final consumers, are crucial. Among these factors, trade barriers combined with low costs of factors of production were not compatible with the coexistence of trade flows and FDI. In OLI paradigm, exports and FDI are substitutes.

According to New Trade Theory models, the sign of the correlation between exports and FDI for each country depends on FDI type, i.e. horizontal versus vertical FDI. Horizontal models of FDI, arguing that foreign markets are served either by exports or by FDI, consider outward FDI as substitutes to exports: in these FDI there is a trade-off between the additional fixed costs of establishing an overseas plant in a foreign market against the costs of exporting abroad (Brainard, 1997). Vertical FDI models present different motivations. Vertical models FDI, predicting the fragmentation of production process in different countries and the integration of different intermediary goods into the final good by a system of trade networks, interpret outward FDI and exports as complements. Jones and Kierzkowski (1990) argued that factor endowments were the key to explain the fragmentation of production in different blocks. In vertical model of FDI, the production process was split into different countries in order to exploit the relative abundance of the factors needed to produce an intermediary good and, then, the different intermediary goods were integrated into the final good by a system of trade networks. As consequence, vertical FDI caused exports among the different stages of the value chain, and, as a results, they were complements with trade.

In light of these considerations, nowadays complementarity and substitutability between exports and outward FDI depends on whether FDI is horizontal or vertical (Moosa, 2002). The empirical evidence on the sign of the connection between exports and outward FDI is mixed (Martinez, Bengoa, \& Sanchez-Robles, 2012). Some studies, like Graham (1996) and Blonigen (2001), Head and Ries (2004), document that FDI and trade behave as substitutes. On average, though, there is a general tendency to reveal complementary relationship between exports and FDI (Barba Navaretti, Venables, \& Barry, 2004).

Papers that investigate empirically this relationship confirm these ambiguous results, but usually focus on few countries, or use data at firm, industry or country level, or focus on intermediate rather than final goods. As highlighted in Fontagnè (1999) the use of data at different levels and for different countries may change significantly the results obtained on FDI and trade being substitute or complement.

Hence, the challenge of this paper is firstly to exploit the database on bilateral FDI but jointly verify if there are similarities or differences in WTN and WIN structures.

\section{Data and Method}

In this work, WTN and WIN are analysed according to two complementary perspectives: a single layer and a multiple layer one. The single-layer perspective analyses each layer of economic integration separately, detecting differences and similarities of the evolution of these networks. The multilayer perspective aims at identifying countries forming cohesive economic groups jointly active in both networks and at describing the resilient 
structure of networks.

We map bilateral merchandise exports (WTN) and bilateral FDI outward stocks (WIN) for a sample of 75 countries from 2001 and 2012. Data are in current US\$ and collected from International Trade Statistics (UNCTAD, 2016) and Bilateral FDI Statistics (UNCTAD, 2014). We focused on FDI outward stocks since data are more stable over time and show less discrepancies if compared to other types of FDI data.

The sample includes countries in different latitudes and stages of economic and financial development and is representative of the world integration since on average, in the whole period, accounts for $96 \%$ of world GDP, about $81 \%$ of world population, $89 \%$ of total exports and $77 \%$ total FDI stocks.

Analysing the first decade of the new millennium allows us to detect how networks change due to exogenous shocks, like 2008 economic crisis.

In the single layer approach, we define network $(N)$ as follows: $N^{t}=\left(V, E^{t}\right)$, where $V$ is set of 75 countries, $E^{t}$ is the set of existing WTN or WIN links over the period $(t)$ from 2001 to 2012.

We compute network indexes to verify which are the driving determinants of WIT a/o WNT relations. In the majority of socio-economic structures, links are not randomly distributed, but they follow particular patterns defined by individual features. In general similar nodes connect with similar nodes, i.e. according to homophily (or assortative) behaviour that drives the choice to establish a link. On the contrary, if the actors associate with dissimilar ones, the network shows disassortative mixing (or heterophily).

We verify the driving forces of links determinants according to two procedures: an exogenous and endogenous procedure. According to the former, we compute the assortativity index (Newman, 2003) considering geographical and economic features of countries. Countries are grouped according to their geographical classification (as in World Bank) or economic classification (as in Chinn-Ito database) (Note 2). The assortativity coefficient ranges between -1 (i.e. perfectly disassortative network) and +1 (i.e. perfectly assortative network), and null value appears when there is no assortative mixing.

According to the endogenous perspective, we exploit nodes features defined within the network in order to identify the causes of existing links. We compute two indexes: degrees correlation and links reciprocity.

The degree correlation is the correlation between degree centrality of each node and its own directly connected nodes. This index indicates an assortativity pattern since it measures if similar nodes, in terms of degree, tend to connect with nodes with comparable degree values. In other words, it verifies if these structures are more similar to a "hub-spoke" with a pivotal country trading with lots of other countries, exchanging exclusively with the pivot, or more similar to a "point to point" system where every country is trading with every other country, with no exclusive or preferential trading partners.

Finally we compute the reciprocity correlation following Gherlaschelli and Loffredo (2004) which can be positive (i.e. reciprocal networks), negative (i.e. anti-reciprocal networks) or null (i.e. neutral networks). If the index is positive, the economic structures show that connections are not randomly distributed, but they follow a mutuality rule: i.e. country $i$ gets linked to country $j$ since an opposite relation is already established, hence transaction costs are lower.

Thanks to the single layer perspective we can detect the main overall features for WTN and WIN and their evolution across the global financial crisis, while a multilayer perspective allows to detect the nestedness of real-world systems (Kivelä et al., 2014; Alves, Mangioni, Cingolani, Rodrigues, Panzarasa, \& Moreno, 2019). Hence we apply the concept of multiplex network (Note 3) and we define network $(G)$ as a triple $G=$ $\left(V, C, E^{t}\right)$, where $V$ is set of countries, $C$ studies WTN and WIN relations, $E^{t}$ is the set of existing links over the period 2001-2012. Treating these networks as multiplex enable us to identify WTN and WIN communities, defined according to the clique (Note 4) percolation method extended to multiplex networks (Tehrani \& Magnani, 2018).

Communities are set of nodes connected more densely to each other, creating cohesive groups. Detecting the structure and the membership of these groups is relevant for several reasons: to verify the resilience to external shock, to detect the existence of preferential exchanging groups and to proxy geopolitical relations (Torreggiani, Mangioni, Puma, \& Fagiolo, 2018).

\section{Results}

WTN and WIN raw values distributions are right skewed, no isolated countries nor sub-groups emerge. All networks are very resilient since removing links with higher values does not fragment networks, but a unique main component emerges: the process of production is complex and globally spread so that either a country 
belongs to it, or is completely excluded and isolated.

QAP correlation confirm that WTN and WIN are associated: coefficients confirm a moderate, positive and significant association between networks (Note 5), but decreasing over time. Hence, networks structures indicate that WTN and WIN are somehow differentiating over time. Despite this, globalisation is at place. In fact removing progressively links from lower to higher values does not fragment the whole structures: all networks are resilient since countries are either connected to a unique largest component, or isolated.

Raw networks do not show interesting structural features, hence for the single layer and multilayer analyses we focused on binary networks detecting flows higher than 100 million US\$, nearly 50\% of total flows in WTN and $20 \%$ of WIN for each year. Results show interesting features confirmed in both types of networks: no subgroups ever emerge, but only large components arise whose dimension is increasing over time. Interestingly WTN largest components are bigger than WIN ones: trade integration is more spread in the world, probably because trading is easier than starting a new investment.

The number of isolated nodes decreases over time and the average degree, i.e. the average number of direct partner per country, is increasing (from 1.5 in 2001 to 4.00 in 2012). This confirms the global value chain theory: the fragmentation of the process of production is so complex and globally spread that a country belongs to it, or is completely isolated.

Focusing on the determinants of generating exchanges, we analyse assortativity. Figure 2 shows the evolution of assortativity indexes in WTN and WIN. A positive value of assortativity index implies that similar countries connect with similar ones, i.e. homophily behaviour drives the choice to establish economic relations. While negative value shows heterophily and null randomly distributed relations.

All values are evolving over time but general trends are similar: same geographical location and reciprocal links facilitate relations (homophile behaviour); while countries that are central in the networks tend to connect with less central partners (heterophil behaviour). Economic development is irrelevant. Same geographical location reflect lower transport costs, and mutual links reinforce reciprocal knowledge and lower transaction costs: both these effects increase the probability to establish a WTN a/o WIN links.

In this decade, WTN and WIN degrees distributions are right skewed confirming that few countries are key players while the majority of countries is peripheral. Despite structural similarities accompanied the evolution of WTN and WIN, pivotal countries are pretty different. In WIN the most central economies are USA and few European countries (i.e. Germany, UK and France) and are firmly central in the whole decade. In WTN USA and Germany leadership has been reached by China.

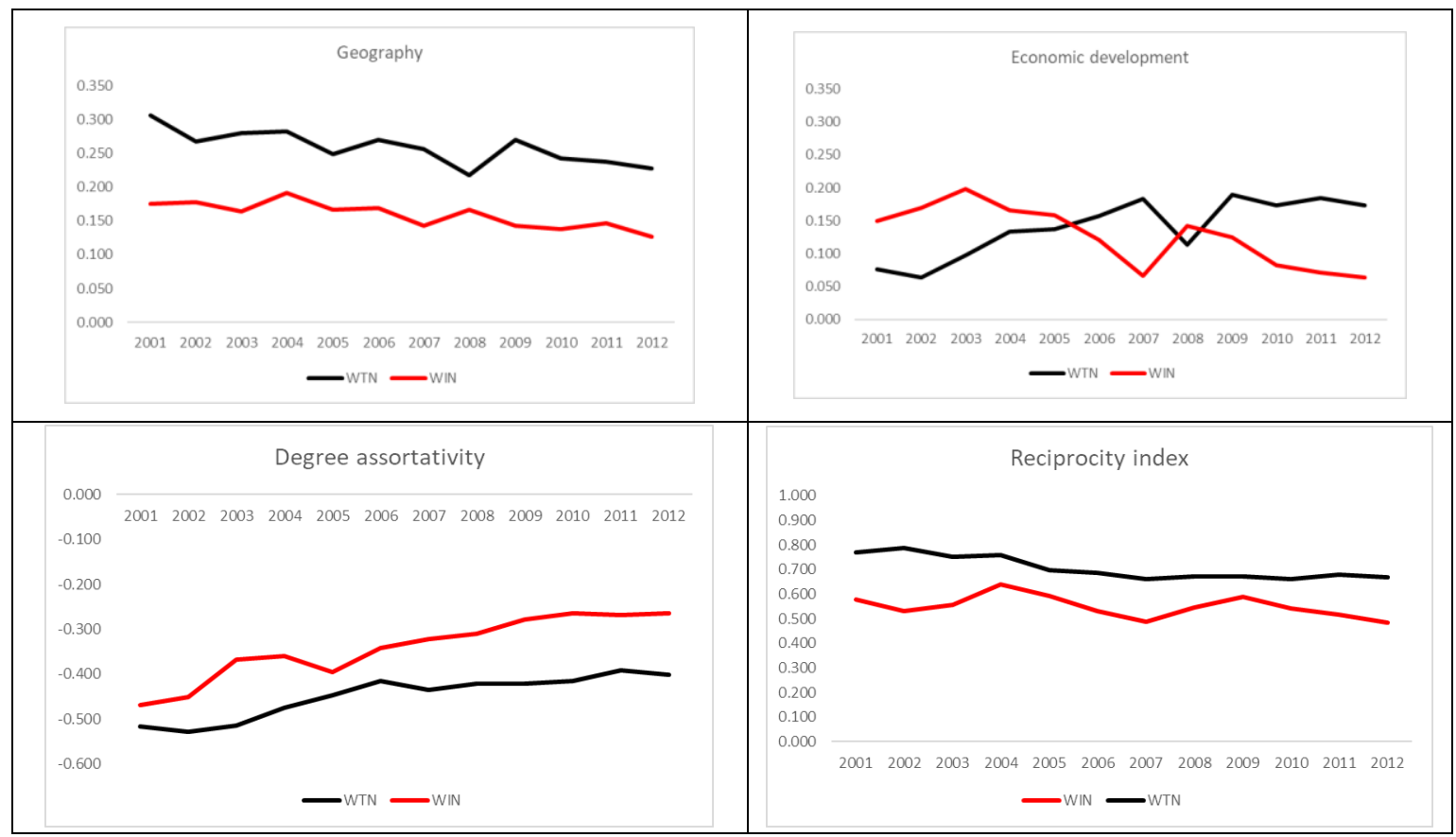

Figure 2. Exogenous and endogenous measures of assortativity 
According to a multi-layer perspective, we computed correlations between Exports and FDI degrees (both indegree and outdegree): values are positive and strong but decreasing over time, suggesting that central or peripheral positions in WTN and WIN are associated but increasingly differentiating (as the case of China leader in WTN but more peripheral in WIN). The positive association suggests that a country's productive and managerial skills could be adopted in both networks type.

Hence we completed the analysis focusing on the identification of communities, or cohesive subgroups.

Column a in Table 1 shows 20 WIN-WTN communities in 12 years whose membership is increasing over time (column b). These communities are geographically based on Europe or in Asia; USA is always included and play a bridging role among different communities; 2 economies (Germany and United Kingdom) are always present in at least one community.

We detect the networks resilience analysing the residual relations apart from these highly cohesive sub-groups: inside communities relations are extremely dense, by definition; but what is crucial is to analyse the remaining sub-structures, apart from communities. In other words: if residual networks contain disconnected and isolated countries, the economic integration is extremely fragile; while if countries create connected sub-groups, globalisation is resilient to negative shocks on communities. During this decade, non-communities subgroups are becoming larger and larger, more and more complex (table 1, columns $\mathrm{c}$ and d) but WIN and WTN are structurally different. Figure 3 include WTN and WIN for 2000, 2005 and 2012 and synthetises these structural differences entirely determined by China.

China is a global trading player China but is excluded from communities, hence the structural features of residual networks are pretty different: in WTN China maintained its trading relations according to a hub and spoke structure, controlling all flows (Figure 3), while in WIN the sub-networks are more egalitarian hence more resilient to economic shocks (Figure 3).

Concluding apart from communities, WIN residual networks are very resilient, while WTN not.

Table 1. Communities and non-communities sub-networks

\begin{tabular}{|c|c|c|c|c|c|c|}
\hline \multirow[b]{2}{*}{ Year } & \multirow{2}{*}{$\begin{array}{c}\begin{array}{c}\text { Number of } \\
\text { Communities } \\
\text { (a) }\end{array} \\
\text { WTN and WIN } \\
\end{array}$} & \multirow{2}{*}{$\begin{array}{c}\begin{array}{c}\text { Members in } \\
\text { Communities } \\
\text { (b) }\end{array} \\
\text { WTN and WIN }\end{array}$} & \multicolumn{2}{|c|}{$\begin{array}{c}\text { Number of } \\
\text { non-communities sub-networks } \\
\text { (c) }\end{array}$} & \multicolumn{2}{|c|}{$\begin{array}{c}\text { Members in } \\
\text { non-communities } \\
\text { (d) }\end{array}$} \\
\hline & & & WTN & WIN & WTN & WIN \\
\hline 2001 & 1 & 7 & 2 & 3 & $3 ; 6$ & $3 ; 2 ; 2$ \\
\hline 2002 & 2 & $3 ; 3$ & 2 & 1 & $4 ; 9$ & 16 \\
\hline 2003 & 1 & 9 & 2 & 2 & $2 ; 12$ & $2 ; 6$ \\
\hline 2004 & 1 & 8 & 2 & 1 & $2 ; 15$ & 15 \\
\hline 2005 & 1 & 8 & 1 & 1 & 21 & 17 \\
\hline 2006 & 2 & $3 ; 10$ & 2 & 4 & 2,18 & $2 ; 2 ; 2 ; 7$ \\
\hline 2007 & 2 & $3 ; 11$ & 3 & 4 & $2 ; 4 ; 21$ & $2 ; 2 ; 2 ; 12$ \\
\hline 2008 & 1 & 9 & 2 & 4 & $2 ; 31$ & $2 ; 2 ; 2 ; 22$ \\
\hline 2009 & 1 & 12 & 3 & 4 & $2 ; 3 ; 22$ & $2 ; 4 ; 4 ; 14$ \\
\hline 2010 & 3 & $3 ; 3 ; 13$ & 3 & 6 & $2 ; 3 ; 23$ & $2 ; 2 ; 2 ; 2 ; 3 ; 12$ \\
\hline 2011 & 2 & $3 ; 21$ & 2 & 2 & $2 ; 13$ & $2 ; 10$ \\
\hline 2012 & 3 & $3 ; 9 ; 5$ & 1 & 1 & 37 & 27 \\
\hline
\end{tabular}

\section{Conclusion}

Policy makers consider FDI and trade crucial for economic integration and development. In this paper we analysed WTN and WIN jointly from 2001 until 2012.

Thanks to the similarity of bilateral data, we are able to depict jointly WIN and WTN structures and their evolution: WTN and WIN are positively associated suggesting that real and financial integration are complement, the global value chain tightly connects all world economies and no countries are isolated. Focusing on the highest flows values (larger than 100 million US\$), homophile patterns arise according to geography and mutual links, while degree correlation confirms that highly connected countries tend to link to dissimilar countries.

Results on 20 communities, i.e. cohesive subgroups of countries, show that geography is the main determinant of WTN-WIN relations both inside and outside communities. USA, UK and Germany are always part of communities without exclusive control of flows, while China, which joins community only in 2011, behaves as a 
star-player in WTN and as a local player in WIN. The Chinese structural position determines the resilience of networks: WIN are more resilient to external shocks than WTN.

This descriptive analysis is mainly devoted to compare WIN and WTN structures highlighting similarities and differences, but further work could focus on three main issues: study of FDI flows, empirical analysis of the relationship between WTN and WIN and finally the determinants of these flows. Due to the quality of the data, we limited our research to FDI stocks, rather than flows, but it would be interesting to analyse the latter in order to trace the structure of FDI variations. Moreover, we verified complementarity between FDI and trade through QAP correlation, but we did not test it empirically with an econometric analysis. Finally, we did not investigate the determinants of WIN and WTN, hence a gravity model could be tested to answer this question.

In conclusion, the SNA techniques adopted in this paper disclosure overall structural analogies between WTN and WIN, rarely analysed jointly, but also sub-network structures that emphasise the differences between these networks, that are apparently very similar.

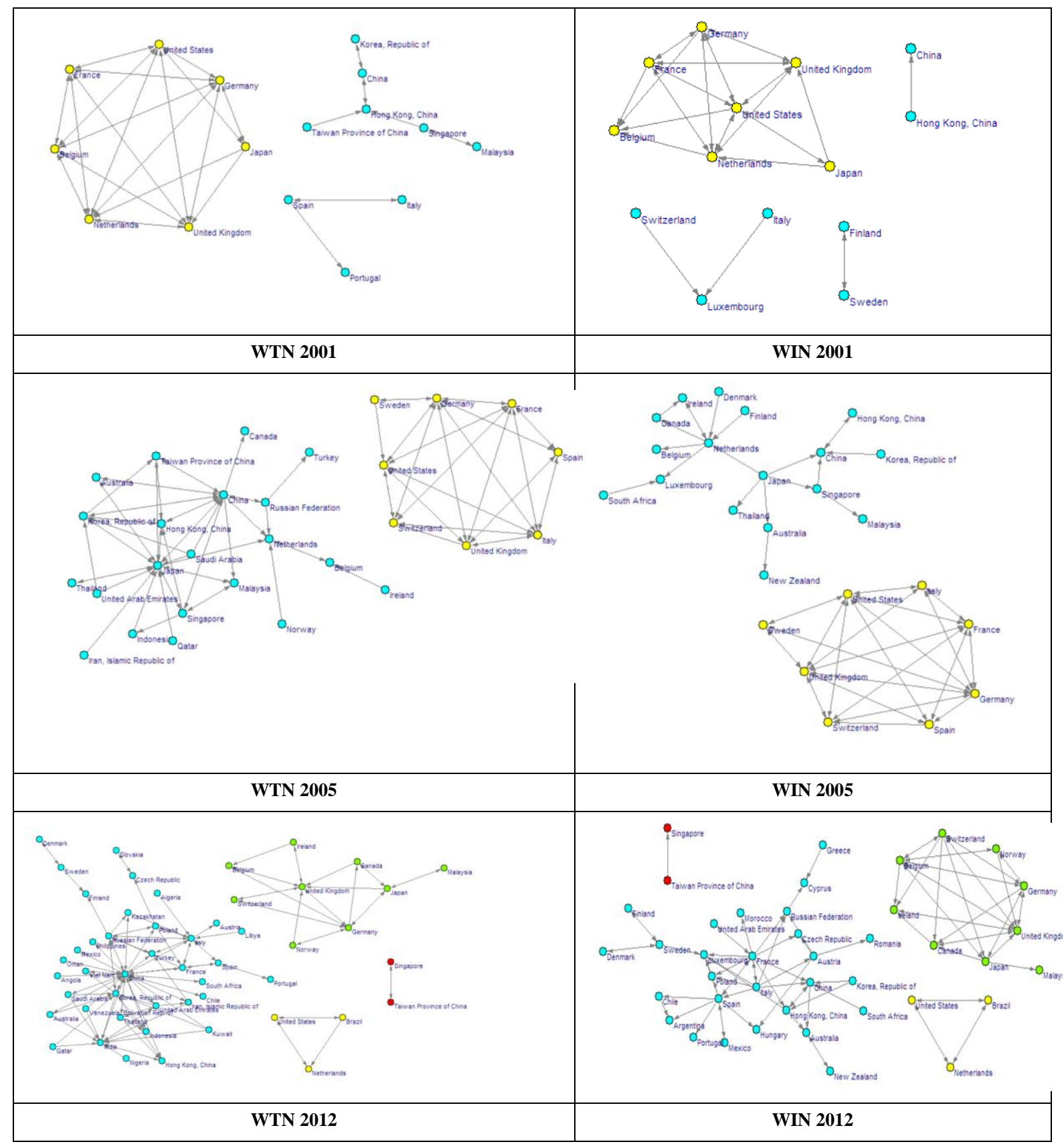

Figure 3. Evolution of communities (yellow, red and green) and non-communities (light blue) 


\section{References}

Alves, L. G. A., Mangioni, G., Cingolani, R. F. A., Panzarasa, P., \& Moreno, Y. (2019). The nested structural organization of the worldwide trade multi-layer network. Scientific Reports, 9, 2866. https://doi.org/10.1038/s41598-019-39340-w

Barabási, A. L., \& Albert, R. (1999). Emergence of scaling in random networks. Science, 286(5439), 509-512. https://doi.org/10.1126/science.286.5439.509

Barba, N. G., Venables, A., \& Barry, F. (2004). Multinational firms in the world economy. Princeton: Princeton University Press.

Barigozzi, M., Fagiolo, G., \& Garlaschelli, D. (2010). Multinetwork of international trade: A commodity-specific analysis. Physical Review E, 81(4), 046104. https://doi.org/10.1103/PhysRevE.81.046104

Barigozzi, M., Fagiolo, G., \& Mangioni, G. (2011). Identifying the community structure of the international-trade multi network. Physica A, 390(11), 2051-2066. https://doi.org/10.1016/j.physa.2011.02.004

Baronchelli, A., \& Uberti T. E. (2018). Exports and Fdi: Comparing Networks in the New Millennium. CRENOS WP 2018/13.

Bénassy-Quéré, A., Coupet, M., \& Mayer, T. (2007). Institutional determinants of foreign direct investment. World Economy, 30(5), 764-782. https://doi.org/10.1111/j.1467-9701.2007.01022.x

Bing, L., Zefang, L., \& Lijian, S. (2018). Evolution of FDI flows in the global network: 2003-2012. Applied Economics Letters, 25(20), 1440-1446. https://doi.org/10.1080/13504851.2018.1430306

Black, D. A., \& Hoyt, W. H. (1989). Bidding for firms. American Economic Review, 79, 1249-1256.

Blonigen, B. A. (2001). In Search of Substitution between Foreign Production and Exports. Journal of International Economics, 53, 81-104. https://doi.org/10.1016/S0022-1996(00)00066-0

Bond, E., \& Samuelson, L. (1986). Tax holidays as signals. American Economic Review, 76, 820-826.

Brainard, S. L. (1997). An empirical assessment of the proximity-concentration trade-off between multinational sales and trade. American Economic Review, 87, 520-544.

Breiger, R. (1981). Structures of economic interdependence among nations. Continuities in Structural Inquiry, 353-380.

De Benedictis, L., \& Tajoli, L. (2011). The world trade network. The World Economy, 34(8), 1417-1454. https://doi.org/10.1111/j.1467-9701.2011.01360.x

Deardorff, A. V. (2001). Fragmentation in simple trade models. North American Journal of Economics and Finance, 12, 121-137. https://doi.org/10.1016/S1062-9408(01)00043-2

Dixit, A. K., \& Grossman, G. M. (1982). Trade and protection with multistage production. Review of Economic Studies, 49, 583-594. https://doi.org/10.2307/2297288

Dueñas, M., Mastrandrea, R., Barigozzi, M., \& Fagiolo, G. (2017). Spatio-temporal patterns of the international $\begin{array}{lllll}\text { merger and acquisition network. Scientific Reports, } & 7(1), \quad 10789 .\end{array}$ https://doi.org/10.1038/s41598-017-10779-z

Dunning, J. H. (1977). Trade, location of economic activity and the MNE: a search for an eclectic approach. In B. Ohlin, P. O. Hesselborn, \& P. M. Wijkman (Eds.), The International Allocation of Economic Activity (pp. 395-418). London: Holmes and Meier. https://doi.org/10.1007/978-1-349-03196-2_38

Dunning, J. H., \& Lundan, S. M. (2008). Multinational enterprises and the global economy. London: Edward Elgar Publishing.

Dunning, J. H. (1979). Explaining changing pattern of international production in defence of eclectic theory. $\begin{array}{lllll}\text { Oxford Bulletin of Economics and } & \text { 269-296. }\end{array}$ https://doi.org/10.1111/j.1468-0084.1979.mp41004003.x

Dunning, J. H. (2009). Location and the multinational enterprise: A neglected factor? Journal of International Business Studies, 40, 5-19. https://doi.org/10.1057/jibs.2008.74

Economou, F., Hassapis, C., Philippas, N., \& Tsionas, M. (2017). Foreign Direct Investment Determinants in OECD and Developing Countries. Review of Development Economics, 21, 527-542. https://doi.org/10.1111/rode.12269 
Faeth, I. (2009). Determinants of foreign direct investment-a tale of nine theoretical models. Journal of Economic surveys, 23(1), 165-196. https://doi.org/10.1111/j.1467-6419.2008.00560.x

Fagiolo, G., \& Mastrorillo, M. (2014). Does Human Migration Affect International Trade? A Complex-Network Perspective. PLoS ONE, 9(5), e97331. https://doi.org/10.1371/journal.pone.0126879

Fagiolo, G. (2010). The international-trade network: Gravity equations and topological properties. Journal of Economic Interaction and Coordination, 5(1), 1-25. https://doi.org/10.1007/s11403-010-0061-y

Fontagné, L. (1999). Foreign direct investment and international trade, 1999/3. OECD Science, Technology and Industry Working Papers. https://doi.org/10.1787/771416201121

Freeman, L. C. (2014). The development of social network analysis - with an emphasis on recent events. In J. Scott, P. J. Carrington (Eds.), The SAGE Handbook of Social Network Analysis (pp. 26-39). London: SAGE Publications Ltd. https://doi.org/10.4135/9781446294413.n3

Garlaschelli, D., \& Loffredo, M. I. (2004). Fitness-dependent topological properties of the world trade web. Physical Review Letters, 93(18), 188701. https://doi.org/10.1103/PhysRevLett.93.188701

Graham, E. (1996). On the Relationship among Foreign Direct Investment and International Trade in the Manufacturing Sector: Empirical Results for the United States and Japan. WTO Staff Working Paper RD-96-008.

Gruber, W., Mehta, D., \& Vernon, R. (1967). The R \& D factor in international trade and international investment of United States industries. The Journal of Political Economy, 20-37. https://doi.org/10.1086/259235

Hanneman, R. A., \& Riddle, M. (2005). Introduction to social network methods. Riverside, CA: University of California, Riverside.

Head, K., \& Ries, J. (2004). Exporting and FDI as alternative strategies. Oxford Review of Economic Policy, 20(3), 409-423. https://doi.org/10.1093/oxrep/grh024

Helpman, E. (1985). Multinational corporations and trade structure. Review of Economic Studies, 52, 443-458. https://doi.org/10.2307/2297663

Horstmann, I. J., \& Markusen, J. R. (1987). Strategic investment and the development of multinationals. International Economic Review, 28, 109-121. https://doi.org/10.2307/2526862

Hubert, F., \& Pain, N. (2002). Fiscal incentives, European integration and the location of foreign direct investment. NIESR Discussion Paper 195. London: National Institute of Economic and Social Research.

Iversen, C. (1936). Aspects of the theory of international capital movements. London: Oxford University Press.

Jones, R. W., \& Kierzkowski, H. (1990). The role of services in production and international trade: a theoretical framework. In R. W. Jones, \& A. O. Krueger (Eds.), The Political Economy of International Trade. Oxford: Basil Blackwell.

Jones, R. W., \& Kierzkowski, H. (2005). International fragmentation and the new economic geography. North American Journal of Economics and Finance, 16, 1-10. https://doi.org/10.1016/j.najef.2004.11.005

Kemp, M. C. (1964). The Pure Theory of International Trade. Englewood Cliffs, NJ: Prentice Hall.

Kim, C. S., \& Park, M. S. (2012). Trade, foreign direct investment and international flow of labor: OECD countries. Journal of International and Area Studies, 1-12.

Kindleberger, C. P. (1969) American Business Abroad: Six Lectures on Foreign Direct Investment. New Haven, CT: Yale University Press.

Kivelä, M., Arenas, A., Barthelemy, M., Gleeson, J. P., Moreno, Y., \& Porter, M. A. (2014). Multilayer networks. Journal of Complex Networks, 2(3), 203-271. https://doi.org/10.1093/comnet/cnu016

Lipsey, R. E. (2007). Defining and measuring the location of FDI output. NBER Working Paper 12996. https://doi.org/10.3386/w12996

MacDougall, G. D. A. (1960). The benefits and costs of private investment from abroad: A theoretical approach. Economic Record, 36, 13-35. https://doi.org/10.1111/j.1475-4932.1960.tb00491.x

Marin, A., \& Wellman, B. (2011). Social network analysis: An introduction. In J. Scott, \& P. J. Carrington (Eds.), The SAGE Handbook of Social Network Analysis. London: SAGE Publications Ltd.

Markusen, J. R. (1984). Multinationals, multi-plant economies, and the gains from trade. Journal of 
International Economics, 16(3), 205-226. https://doi.org/10.1016/S0022-1996(84)80001-X

Martinez, V., Bengoa, M., \& Sanchez-Robles, B. (2012). Foreign Direct Investment and Trade: Complements or Substitutes? Empirical Evidence for the European Union. Technology and Investment, 3, 105-112. https://doi.org/10.4236/ti.2012.32013

Metulini, R., Riccaboni, M., Sgrignoli, P., \& Zhu, Z. (2017). The indirect effects of foreign direct investment on trade: A network perspective. The World Economy, 40(10), 2193-2225. https://doi.org/10.1111/twec.12504

Milgram, S. (1967). The Small-World Problem. Psychology Today, 2(1), 61-67. https://doi.org/10.1037/e400002009-005

Moosa, I. A. (2002). Foreign Direct Investment: Theory, Evidence and Practice. New York: Palgrave. https://doi.org/10.1057/9781403907493

Mundell, R. A. (1957). International trade and factor mobility. American Economic Review, 47(3), 321-335.

Nemeth, R. J., \& Smith, D. A. (1985). International trade and world-system structure: A multiple network analysis. Review (Fernand Braudel Center), 8(4), 517-560.

Newman, M. E. (2003). Mixing patterns in networks. Physical Review E, 67(2), 026126. https://doi.org/10.1103/PhysRevE.67.026126

O’Rourke, K. H., \& Williamson J. G. (2002). When did Globalisation Begin? European Review of Economic History, 6(1), 23-50. https://doi.org/10.1017/S1361491602000023

OECD. (2002). Foreign Direct Investment for Development: Maximising Benefits, Minimising Costs, Paris.

Prebisch, R. (1962). The Economic Development of Latin America and Its Principal Problems. Economic Bulletin for Latin America, 7, 1-22.

Serrano, M. Á., \& Boguñá, M. (2003). Topology of the world trade web. Physical Review E, 68(1), 015101. https://doi.org/10.1103/PhysRevE.68.015101

Smith, D. A., \& White, D. R. (1992). Structure and dynamics of the global economy: network analysis of international trade 1965-1980. Social Forces, 70(4), 857-893. https://doi.org/10.2307/2580193

Snyder, D., \& Kick, E. L. (1979). Structural position in the world system and economic growth, 1955-1970: A multiple-network analysis of transnational interactions. American Journal of Sociology, 1096-1126. https://doi.org/10.1086/226902

Su, T. (1995). Changes in world trade networks: 1938, 1960, 1990. Review (Fernand Braudel Center), 431-457.

Tehrani, N. A., \& Magnani, M. (2018). Partial and overlapping community detection in multiplex social networks. International Conference on Social Informatics, 15-28. https://doi.org/10.1007/978-3-030-01159-8_2

Torreggiani, S., Mangioni, G., Puma, M. J., \& Fagiolo, G. (2018). Identifying the community structure of the food-trade international multi-network. Environmental Research Letters, 13(5). https://doi.org/10.1088/1748-9326/aabf23

UNCTAD. (2009). Training Manual on Statistics for FDI and the Operations of TNCs: Volume I - FDI Flows and Stocks. New York and Geneva: United Nations.

UNCTAD. (2014). Bilateral FDI Statistics. New York and Geneva: United Nations.

UNCTAD. (2016). International Trade Statistics. New York and Geneva: United Nations.

Van Rossem, R. (1996). The world system paradigm as general theory of development: A cross-national test. American Sociological Review, 508-527. https://doi.org/10.2307/2096362

Vernon, R. (1966). International investment and international trade in the product cycle. The Quarterly Journal of Economics, 190-207. https://doi.org/10.2307/1880689

Wallerstein, I. (1974). The modern world system Academic Press. New York: Academic Press.

Watts, D. J., \& Strogatz, S. H. (1998). Collective dynamics of 'small-world' networks. Nature, 393(6684), 440. https://doi.org/10.1038/30918

Zhou, M., Wu, G., \& Xu, H. (2016). Structure and formation of top networks in international trade, 2001-2010. Social Networks, 44, 9-21. https://doi.org/10.1016/j.socnet.2015.07.006 


\section{Notes}

Note 1. In some cases bilateral data are not matching because FDI play also strategic role in the economy, hence countries omit figures (UNCTAD, 2009).

Note 2. We used 2015 updated version available on line: http://web.pdx.edu/ ito/Chinn-Ito_website.htm. This database classifies countries according to their capital account openness. We used this definition since countries classifications are pretty stable, hence comparable to the geographical definition. We defined 3 groups of countries: emerging economies, industrialised economies or less developed countries.

Note 3. A multiplex network is a sub-type of multi-layer network. A multilayer network is a network with several layers which may have different nodes and different types of edges (Kivelä et al., 2014).

Note 4. "A clique is a sub-set of a network in which the actors are more closely and intensely tied to one another than they are to other members of the network" (Hanneman \& Riddle, 2005).

Note 5. From 2001 to 2012 QAP correlation is positive and ranging between 0.531 and 0.619 and all values are statistically significant at $1 \%$.

\section{Copyrights}

Copyright for this article is retained by the author(s), with first publication rights granted to the journal.

This is an open-access article distributed under the terms and conditions of the Creative Commons Attribution license (http://creativecommons.org/licenses/by/4.0/). 